\title{
Community values for environmental protection in a cane farming catchment in Northern Australia: A choice modelling study
}

\author{
T. Mallawaarachchi ${ }^{*}$, R. K. Blamey ${ }^{\ddagger}$ M. D. Morrison ${ }^{\S}$, \\ A. K. L. Johnson" and J. W. Bennett ${ }^{\dagger t}$
}

Choice modelling is an emerging approach to estimating the non-use values of environmental services with multiple attributes. In this paper, results are reported of a choice modelling study conducted in the Herbert River District of North Queensland to estimate the value placed on the protection of natural vegetation in areas suitable for cane production by the local community. Resource use options that vary in the level of environmental protection and the level of agricultural production were presented as a series of choice sets and respondents were asked to choose among a set of three discrete alternatives in a given choice set. The alternatives in each choice set were described by four attributes, pertaining to the area of teatree woodlands, the area of vegetation along rivers and in wetlands, regional income from cane production, and an environmental levy. The responses were analysed together with socio-economic data using a nested-logit discrete-choice model to estimate the community willingness-to-pay for the protection of natural vegetation. The results indicate that the environmental values of wetlands are comparable to returns from commercial production of sugar cane and that the values of teatree woodlands are comparable to returns from extensive grazing. It is argued that land allocation policies should recognise these values in tandem with commercial benefits of production to ensure that resources are used more efficiently.

(C) 2001 Academic Press

Keywords: sugar industry, non-use values, choice modelling, externality effects.

\section{Introduction}

In recent times, a great deal of emphasis has been placed on the management of harmful externalities on the natural environment resulting from production activities. This follows a growing understanding of the implications of declining environmental quality on life support systems and the future productive capacity of our ecosystem, and a progressive change in community attitudes towards greater environmental care. Although the value of environmental

An earlier version of this paper was presented to the 43 Annual Conference of the Australian Agricultural and Resource Economics Society, Christchurch, New Zealand, 20-22 January 1999.

Email of corresponding author: Thilak.Mallawaarachchi @jcu.edu.au resources such as rainforests, wetlands and coral reefs have been reflected in the rapid increase in demand for nature-based tourism and recreational activities, it is only recently that economists have begun to assess the economic value of environmental resources in a manner comparable with production values of agriculture or industry (Pearce, 1993; Smith, 1996).

While valuation studies at global (Costanza et al., 1997), regional (Menkhaus and Lober, 1996) and local (Morrison et al., 1999; White and Lovett, 1999) levels have proved useful in highlighting the economic importance of nature conservation, such information has rarely been used directly to guide decisions to allocate resources between production and environmental uses. In particular, both planners and economists have largely ignored
* Corresponding author

†CRC for Sustainable Sugar Production and James Cook University, Si George Fisher Building,

Townsville Qld 4811 Australia (Formerly CSIRO Tropical Agriculture, Davies Laboratory, Townsville)

$\ddagger$ Program Visitor, Urban Research Program, Research School of Social Sciences, Australian National University, Canberra, ACT 0200, Australia

$\S$ School of Marketing and Management, Charles Sturt University, Panorama Avenue, Bathurst NSW 2795, Australia

I CSIRO Tropical Agriculture and CRC for Sustainable Sugar Production, 120, Meiers Rd, Indooroopilly Q/d 4068, Australia

†† National Centre for Development Studies, Australian National University, Canberra ACT 0200, Australia

Received 20 August 1999; accepted 7 March 2001 
the extent of trade-offs between economic and environmental values in irreversible decisions to convert natural areas to agricultural production. Failure to quantify environmental values in matching terms with commercial values of production often results in an implicit value of zero being placed on forgone environmental benefits. This encourages resource allocations to be biased against preserving natural areas. Many agricultural development activities have come under much criticism because of this inadequacy.

Clearing of natural vegetation for sugar cane growing is an issue of controversy in Australia, because it reduces the habitat of a number of threatened and non-threatened species. Society needs to compare the economic benefits of sugarcane expansion with the potential environmental losses resulting from land clearance. Lack of information on the value of these potential environmental losses makes the allocation decisions open to controversy and increases the likelihood of sub-optimal resource use. This parallels many such conflicts over land development and conservation occurring throughout the world such as deforestation, mining and fisheries development.

The sugar industry, located along the Queensland coast is one of Australia's important rural industries. Most sugarcane is grown within $80 \mathrm{~km}$ of the eastern seaboard, mainly in high rainfall areas across 22 river catchments. The spectacular coastline, attractive surf beaches, recreational fishing, Ramsar listed wetlands, and numerous National Parks attract a growing number of tourists to the Queensland coast. The location of the sugar industry in close proximity to two unique natural monuments, the offshore Great Barrier Reef and the inshore Wet Tropics rainforests, both listed under the World Heritage Convention, makes the northern Queensland coast an environmental region of international significance.

Recent growth of the sugar industry, featured primarily by area expansion, has strengthened the position of the industry in the regional economy, while also exposing the industry to a range of environmental conflicts (Mallawaarachchi, 1998). According to Mary Maher and Associates (1996) and Johnson et al. (1997), the most pressing issues arise from an expansion of the area of assigned land for cane growing.
In the absence of careful land use planning, expansion can create problems such as: altering the existing drainage regime, including wetlands, poorly drained coastal plains and coastal waterways; clearing of critical habitat and significant vegetation communities; disruption to aquatic life, water quality and fish breeding grounds; and fragmentation of previous integral native habitat.

Additional environmental problems, also shared with other intensive agricultural industries, include diffuse source pollution arising from runoff of pesticides, fertilisers and mill effluents, and problems associated with the consumptive use of water for irrigation (Johnson et al., 1997; Mary Maher and Associates, 1996; Rayment and Neil, 1997). These environmental concerns have been the source of conflict between economic and environmental objectives of land use within the cane growing regions of Australia. In particular, industry expansion has raised environmental concerns about the effects of land clearing and about nonpoint source pollution from an expanding cane area. Concerns about present policies stem from the perception that existing policies have led to an excessive allocation of resources to sugar production and inadequate conservation of the natural environment. The industry has responded to community concerns by adopting a voluntary Code of Practice for Canegrowing (Canegrowers, 1998), aimed at mitigating the adverse environmental effects of on-farm practices. The focus of this paper is on the assessment of community attitudes to environmental protection, in particular determining the non-market values of wetlands and natural woodlands that may be cleared to grow sugarcane.

Similar to many agricultural regions around the world, the economic base of coastal Queensland is undergoing change. Emergent sectors such as tourism and recreation, urban infrastructure and public utilities are competing for natural resources hitherto primarily used for agriculture. Co-location of incompatible uses, such as nature conservation and urban and agricultural development, enhances the potential for resource use conflict. There is evidence that the environmental effects of sugar industry operations are of concern 
to both the population at large and the communities within particular sugar growing regions (Gutteridge, Haskins \& Davey, 1996).

Commercial benefits of the sugar industry are measurable both at the local and the national levels, because its output is traded. In contrast, there are no specific market transactions for the attributes of the natural environment that are being replaced or altered through sugar industry developments. As a consequence, resource allocation decisions are made without information on the monetary value of the environmental consequences of industry developments. Analysis of community attitudes to environmental protection in cane-growing regions can therefore contribute to the policy debate and offer insights on ways to achieve more efficient resource use.

From a policy perspective, the aim of resource allocation is to achieve the maximum social benefit from alternative uses. When uses are not compatible, or are mutually exclusive, the aim is to use resources in the best alternative. This requires estimating the level of benefits sacrificed to achieve a more preferred outcome. Often, such values are not directly available. Land allocation for agricultural development in particular encounters such trade-offs where choices need to be made between prospective uses for which commensurate benefit estimates are not available. Here, we present the results of a choice modelling study that was used to estimate willingnessto-pay for the protection of areas of natural vegetation in the Herbert River District of north Queensland that are potentially suitable for cane growing. This tropical catchment has experienced significant landuse change since the 1860s following the introduction of sugar cane (Johnson et al., 1998). This study forms a core component of a research program to develop a strategic regional resource assessment (SRRA) framework to evaluate economic-environmental trade-offs in regional resource use. The opportunity costs of land use estimated in this study are integrated with commercial values of production in a regional model of the sugar industry to evaluate alternative options for land allocation in sugarcane production (Mallawaarachchi and Quiggin, 2001).

\section{Methods}

\section{Non-market valuation}

In the absence of direct market prices to estimate the values placed by consumers on non-market goods such as natural vegetation and wetlands, willingness-to-pay can be derived using stated preference techniques, which seek to establish preference relations of individuals by observing their responses to hypothetical circumstances.

The contingent valuation method (CVM) is a well-known stated preference technique (Mitchell and Carson, 1989). In general, CVM studies focus on problems involving a precise scenario represented by one alternative state and the status quo. For example, respondents are asked about their willingness-to-pay for the alternative by choosing to pay a randomly selected bid from a pre-specified range of bids (say AUS \$1-100 as a levy on land rates), by not paying the bid or by choosing 'I don't know' as a response. CVM studies are frequently used to evaluate both use and non-use values for various environmental commodities (Morrison et al., 1996). However, its use in situations where multiple options and several attributes are being considered is generally problematic because of the costs involved in undertaking separate surveys to evaluate each option (Streever et al., 1998). Cameron and Quiggin (1994) discuss estimation difficulties in CVM studies. One important difficulty is that of valuing benefits of environmental preservation in a manner that is useful for land-use planning. These difficulties have prompted the development of alternative approaches based on suitability scores to address valuation difficulties (Hanink and Cromley, 1998).

More recent developments such as choice modelling (Blamey et al., 1999, 2000; Morrison et al., 1999) are better suited to use in land-management problems, since they are concerned with modelling choices varying over a range of characteristics, rather than with the estimation of willingness-to-pay for a single policy option.

\section{Choice modelling}

A choice modelling study typically involves two stages: a survey to elicit responses for a 
set of options, and an econometric analysis to estimate a utility model whereby willingnessto-pay estimates are derived. During the survey, respondents are presented with several sets of resource use options and are asked to choose their preferred option from each set. Respondents' choices are guided by the cost of achieving each option and the associated benefits as explained with the use of different attributes. By systematically varying the cost parameter and the associated benefits represented as changes in the level of environmental attributes within an experimental design, responses from individuals are obtained for a range of attribute levels.

Developed originally for application in marketing and transport studies (Louviere and Hensher, 1982), choice modelling is increasingly an accepted option in environmental assessments in recent studies (Blamey et al., 1999, 2000; Diener et al., 1998; Morrison et al., 1999). For example, Adamowicz et al. (1998) compare the use of contingent valuation and choice modelling to measure passive use values of woodland caribou habitats in Alberta. They highlight the following advantages of the CM approach: (1) the method provides a richer description of the attribute trade-offs that individuals are willing to make; and (2) the welfare estimates from the CM have smaller variances. The focus on attributes in the CM method makes it suitable for estimating both the values of attributes as well as situational changes. An important feature that favours the use of $\mathrm{CM}$ in environmental valuation is the ability to determine the relative importance of commercial, social and environmental factors in the make-up of non-use values. A choice model can estimate the impact of environmental quality attributes, employment opportunities, as well as monetary factors such as a tax or a levy in the determination of choice amongst alternatives (Morrison et al., 1999). This is particularly useful in natural resource management where tradeoffs between natural and man-made goods and services are the primary focus in policy development.

While CM has information efficiency advantages relative to CVM, it does have several limitations. While some proponents argue that CM is likely to be less affected than CVM by certain biases (Bennett, 1996), CM estimates are yet liable for inefficiencies caused by protest responses (such as payment vehicle bias) and yea-saying (Morrison et al., 2000). The design of a choice modelling application is also relatively complex. For example, in some circumstances it can be difficult to define attributes for an environmental change, and to select appropriate levels for those attributes.

Issues related to questionnaire design, survey administration and payment vehicle are as applicable to CM as they are for CVM (Mitchell and Carson, 1989). The theoretical basis of choice modelling is given in the Appendix.

\section{Herbert River District Study}

The Herbert River District is a major sugar cane growing region in Australia. In 1997, the district produced about 5 million tonnes of cane, with a value of AUS $\$ 235$ million to the local region. Over the past 10 years the sugar industry in the Herbert has been expanding at a rate faster than Australia's sugar industry overall. Whilst the expansion of cane growing areas provides benefits to the Herbert district in the form of income and jobs, it often requires the clearing of native vegetation. Clearing native vegetation and draining wetlands diminish the ecological integrity of natural habitats and encourage the spread of invasive species. For example, in the Herbert the fish habitat values of remnant floodplain wetlands have been severely reduced and the habitat for species such as the Eastern Grass Owl (Tyto longimembris) that occupies grass-tussocks in wetlands and adjoining areas have been similarly affected (Vella, 1997) as a consequence of agricultural development (Johnson et al., 1998). Clearing of vegetation alongside rivers and in wetland areas for cane growing has increased steadily since the 1940s in the Herbert River District. Since 1980 , nearly $5 \%$ of the total land area (24 000 ha) has been cleared. Further clearing is expected in the future, although at a slower rate because of limitations in the available mill capacity to process cane.

As a consequence of active community interest and greater environmental awareness, the Australian sugar industry is showing a growing interest in environmental management. The voluntary environmental 
code of practice adopted recently by the cane producers covers ways of minimising environmental impacts of cane growing (Canegrowers, 1997). For most cane growers, however, following the code of practice would mean incurring financial costs, in terms of reduced production or increased expenditure. However, lack of environmental compliance by canegrowers would lead to greater environmental decline in canegrowing regions and a greater likelihood of policy intervention to protect the natural environment.

Continued environmental decline could also have impacts on the nearby Great Barrier Reef Marine Park (Rayment and Neil, 1997). Moreover, expansion of cane into more marginal land may not be financially viable, instead production may be increased on existing land by following sustainable management practices that have the capacity to increase yields (Bramley et al., 1998).

The objective of the Herbert study is to develop a systematic approach to ascertain community values for environmental protection in a cane-growing region, for incorporation in land-use planning. The planning framework, SRRA, incorporates environmental and social concerns of resource use into a decision analysis framework. A key feature of the framework is a linear programming model, Cane Land Allocation Model (CLAM). CLAM takes into account the biophysical attributes that impact on the productive potential of land, opportunity costs of land brought under cane production, and the demand for cane supplies from the local mills to evaluate net social benefits of alternative cane expansion scenarios (Mallawaarachchi and Quiggin, 2001). The aim is to identify best practicable land-use options that maximise regional profits and minimise environmental externalities in land allocation. Within this allocation framework, the community willingness-to-pay estimates derived in this choice modelling study provide the basis for accounting for the opportunity costs of clearing natural vegetation in areas suitable for cane expansion.

\section{The sample}

To estimate statistically, willingness-to-pay as a function of attributes of the vegetation types, data pertaining to socio-economic status and the economic benefits of cane growing were collected for a sample of Herbert residents by means of a mail survey. Using the electoral register as a sampling frame, 810 respondents were selected following a systematic sampling procedure (Cochran, 1977). The population frame consisted of $\mathrm{N}=23193$ members listed according to the alphabetical order. To select a sample of $n=810$ from this list, we set $N / n$ equal to integer $\mathrm{k}=29$. $\mathrm{A}$ number $\mathrm{j}$ between 1 and $\mathrm{k}$ was selected at random and sampling units $\mathrm{j}$, $j+k, j+2 k$ up to $j+(n-1) k$ were selected from the list to form the sample. ${ }^{1}$

\section{Questionnaires}

The development of the questionnaire used in the study followed systematic interaction between the research team and the target population. Two focus group meetings (Morrison et al., 1997), attended by a group that represented a cross section of the Herbert community provided the means to incorporate the diversity of views of the target population at the planning stage. ${ }^{2}$ These participants received a gratuity for attendance at the meeting.

Eleven participants attended the first meeting, where the focus was to elicit information on the awareness of environmental issues in the Herbert and to assess the suitability of alternative ways of organising choice attributes. In particular, the meeting was used to resolve the issues relating to the level of vegetation protection and means to achieve such protection, such as by offering incentives to canegrowers to give up land clearing.

The 2-h meeting offered an effective way to finalise the choice of a payment vehicle, to determine the number of environmental attributes best suited for inclusion in the survey, and to gauge the level of support for the proposed payment vehicle used in the questionnaire. It also provided an opportunity to

\footnotetext{
${ }^{1}$ Catchment boundaries and that of the electoral district do not coincide, and about $20 \%$ of the listed addresses were outside the catchment. Whenever such addresses were encountered, they were omitted and the next address was selected

2 The first four authors were present at the initial meeting, which was conducted by Mark Morrison and Russell Blamey. The first author and a research assistant conducted the second meeting.
} 
test alternative ways of formatting the choice sets. Finally, the group was used to determine language compatibility across interest groups, and the nature of the information that would need to be provided to survey respondents to explain alternative choice scenarios in the survey booklet.

The second focus group, which consisted of 10 individuals, was primarily used as a trial or a pre-test. This group was asked to complete a draft version of the questionnaire. Feedback received following the pre-test was used to improve overall presentation, in particular the clarity of the questions asked, and to minimise the perceived bias of information provided. This process was used to ensure that the chosen attributes were relevant to participants, and that the survey questionnaire and the accompanying pamphlet delivered a consistent and unbiased message in meeting the objectives of the survey.

The questionnaire ${ }^{3}$ was set out in a 20-page B5 booklet with a card cover. It included a page of instructions, three main sections of the survey and two blank pages to gather any respondent comments. Section one included two questions to assess respondents' awareness of general issues raised in the survey compared to other social issues to provide a 'frame' for the specific issues being addressed. This section also included a description of common land-use issues faced in the Herbert and presented a package of options for managing land-use in the district. A map indicated the location of the district and a pie chart presented the distribution of land uses in 1997. Section two comprised the choice sets, while the last section included a series of questions to gather attitudinal and socioeconomic information.

\section{Environmental attributes and the payment vehicle}

The selection of environmental attributes for environmental valuation studies is guided by both theoretical and practical considerations. Conceptually, the aim is to construct a demand function for an environmental good described with the use of attributes that are measurable, relevant and correspond to

$\overline{3}$ The questionnaire and the information pamphlet are available from the corresponding author. changes in people's perceptions. For these reasons, Blamey et al. (1997) argue that preference need to be given to those attributes that are demand relevant, policy relevant, and measurable. The use of such criteria, and the considerations such as the reliability of available information resulted in a list of several potentially suitable attributes. These included the loss in area of wetlands in the region, loss in area of melaleuca woodlands in the region, income loss to the region (due to land-clearing restrictions), etc, which were considered potentially suitable as choice attributes for the Herbert study, at the initial planning stage.

The final selection of attributes, and the design of specific labels were assisted by deliberations at focus group meetings, and consultation with relevant authorities with regard to correct usage of terms. The final choice of the attributes used in the study was influenced by considerations including the nature of estimates to be produced from the survey, resources available and the complexity of the survey. The levels of environmental attributes were chosen with reference to land-use change studies in Herbert (Johnson et al., 1998) and expert advice. The objective was to incorporate a set of values that are internally consistent, and fall within an acceptable range based on available evidence.

Two environmental attributes were described in the questionnaire and the accompanying pamphlet. The pamphlet described the sugar industry and the natural vegetation in Herbert, represented by the teatree woodlands and vegetation along rivers and wetlands. The aim of the pamphlet was to provide an unbiased picture of the costs and benefits associated with the two landuse alternatives. The extent and the rate of decline of teatree woodlands, and the vegetation along rivers and in wetlands were presented along with income in the region derived from cane growing. All scenarios were projected to 2005 . An incentive scheme to minimise environmental impacts of cane growing was described. The scheme was to be funded by an annual levy on land rates, and the scheme would prevent some land being developed for cane growing.

Land rates were used as the payment vehicle, because it is a general instrument used by the local shire to collect revenue to 
finance local services. This payment vehicle is susceptible to a degree of protest among some sections of the population, which creates the possibility of a bias towards the status quo (Samuelson and Zeckhauser, 1988).

\section{The choice sets}

The second section of the questionnaire included nine choice sets. Each choice set contained three alternative options. Option A represented the status quo. Options B and $\mathrm{C}$ each represented a level of environmental and regional income outcomes achievable with the incentive scheme, as well as the costs in terms of the levy to fund the scheme. Each of the options was described using four attributes (the levy, income in region, area of teatree woodlands, and the area of vegetation along rivers and in wetlands projected to 2005). Each attribute was specified at three levels, except for the levy, which was specified at AUS $\$ 0$, AUS $\$ 10$, AUS $\$ 50$ and AUS $\$ 100$. The status quo option was linked to the zero levy. Respondents were asked to choose one option based on the attribute information, which indicated the cost of implementing each option and the expected benefits. A sample choice set is given in Figure 1.

An orthogonal experimental design was used to assign attribute levels to options. This ensured that the attributes varied independently of one another and that their effects on respondents' preferences could be isolated. A fractional factorial design was used to allocate the 81 choice configurations to nine blocks of nine choice sets, over nine versions of the questionnaire.

The questionnaire booklet, the accompanying pamphlet, a covering letter and a postage paid envelope were dispatched by mail to the 810 respondents in the last week of June 1998. A follow-up letter was sent to all failing to reply by July 15 . A second follow-up note with a replacement set of documents was

Question 3

If options $\mathrm{A}, \mathrm{B}$, and $\mathrm{C}$ were the $\mathbf{O N L Y}$ available available options, which one would you choose?

\begin{tabular}{|l|c|c|c|}
\hline \multicolumn{1}{|c|}{ Outcomes } & $\begin{array}{c}\text { Option A } \\
\text { With } \\
\text { current } \\
\text { practice }\end{array}$ & $\begin{array}{c}\text { Option B } \\
\text { With } \\
\text { incentive } \\
\text { scheme }\end{array}$ & $\begin{array}{c}\text { Option C } \\
\text { With } \\
\text { incentive } \\
\text { scheme }\end{array}$ \\
\hline $\begin{array}{l}\text { Annual levy on land rates } \\
\text { per household to fund incentive scheme) }\end{array}$ & None & $\$ 100$ & $\$ 50$ \\
$\begin{array}{l}\text { Income in region in 2005 } \\
\text { Currently } \$ 235 \text { million per annum and increasing }\end{array}$ & $\$ 400$ million \\
$\begin{array}{l}\text { Teatree woodlands in 2005 } \\
\text { Currently 21,000 ha and declining }\end{array}$ & $\begin{array}{c}\$ 400 \text { million } \\
\text { Vegetation along rivers and in wetlands in 2005 } \\
\text { Currently 2300 ha and declining }\end{array}$ & $\begin{array}{c}12,000 \\
700 \text { hectares }\end{array}$ & 250 hectares \\
hectares & 250 hectares \\
\hline
\end{tabular}

I would choose Option A

(continue currrent practice)

I would choose Option B

I would choose Option C

Don't know

Figure 1. A choice set used in the Herbert Study. 
sent to those initial recipients of the questionnaire, who did not respond by 4 August 1998. All responses received by the cut-off date, 21 August 1998, were included in the survey analysis.

\section{Survey analysis and model development}

A total of 226 complete responses was received. After accounting for those removed from the initial sample (Table 1), this represented a $32 \%$ response rate. This was considered adequate given the complex nature of the survey (Mitchell and Carson, 1989). This high level of non-response is, however, a limitation that could reduce the reliability of estimates drawn from the survey. This will be discussed below.

\section{Pre analysis}

Following editing for omissions and obvious misreporting, the final data set contained

Table 1. Response statistics

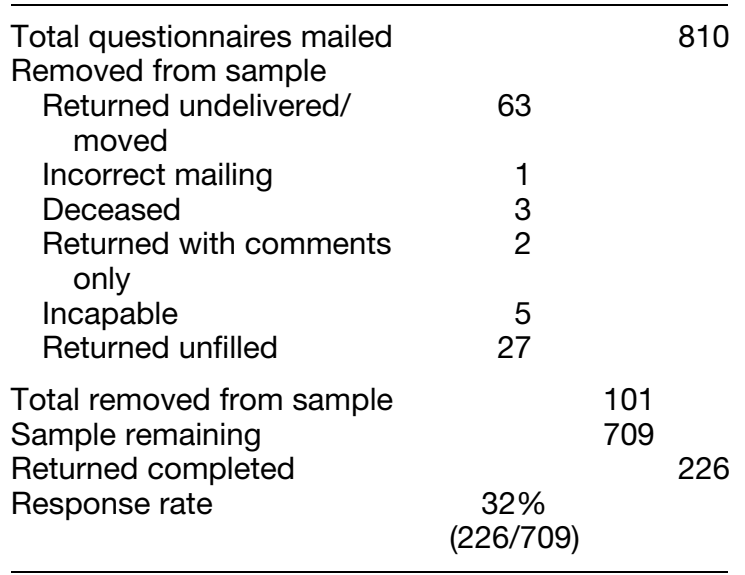

221 valid responses. The mean socio-demographics of the respondents are shown in Table 2. The Queensland population and the population of Herbert district are statistically comparable in many respects. However, the Herbert population is more highly reliant on the rural industry for employment (Australian Bureau of Statistics, 1998).

The sample of Herbert population that responded to the choice modelling survey differed somewhat from that of the Herbert population reported by the Australian Bureau of Statistics. Twenty two per cent of respondents had completed year 12 or achieved a higher level of formal education. A significant proportion (43\%) is employed in the rural industry. The mean age of the respondents was 48 years compared to 38 and 39 for Queensland and Herbert population based on 1996 Census of Population (Australian Bureau of Statistics, 1998). These discrepancies can arise in mail surveys (Streever et al., 1998) and this in itself does not invalidate the results (Mitchell and Carson, 1989). It must be noted that the electoral register used as the sample frame includes individuals older than 18 years, and that itself can raise the mean age compared to the population statistics derived from a census. However, there could be a potential bias in the sample estimates because the high level of nonresponse could have led to a biased sample. Therefore, caution is necessary in interpreting results over the entire Herbert population, and in particular beyond the Herbert district.

In view of this potential problem, efforts were made to minimise non-response bias by including several socio-demographic variables in the discrete choice model estimated. The variables were adjusted so that

Table 2. Socio demographics of survey respondents

\begin{tabular}{lccc}
\hline Socio-demographic & $\begin{array}{c}\text { Population } \\
\text { estimate } \\
\text { for Herbert }\end{array}$ & $\begin{array}{c}\text { Sample } \\
\text { estimate for } \\
\text { Herbert }\end{array}$ & $\begin{array}{c}\text { Population } \\
\text { estimate for } \\
\text { Queensland }\end{array}$ \\
\hline Age (mean >17 years) & 39 & 48 & 38 \\
Sex (\% male) & 52 & 63 & 49.7 \\
Education (\% >12 year) & 7.9 & 22 & 14.3 \\
Persons employed in rural industry (\%) & 15 & 43 & 4.7 \\
Household income (AUS \$ annual) & 33280 & 40572 & 32188 \\
Employment (\%) & 92 & 96 & 90.4 \\
\hline
\end{tabular}

Source: Australian Bureau of Statistics (1998) and survey data. 
they reflected population rather than sample means.

\section{Estimation of the choice model}

A nested logit model (see the Appendix) was estimated to analyse the relationship between the probability of the choice response and the dollar amount represented by the levy (Hanemann, 1984), using limited-dependent variable econometric analysis software, LIMDEP (Greene, 1998). The respondents' decision problem was modelled by grouping the two environmental improvement alternatives in one branch of the decision tree and the status quo or do-nothing option in the other. The branch-choice equation emulated the respondents choosing between 'doing something' and 'doing nothing' at the first branch-level. The utilities of their choice depended on an alternativespecific constant (ASC) (ASC3 in Table 3) and its interaction with household income, an income-dummy representing undisclosed household income, respondent age, and the appreciation of the environmental values of the preservation options measured through respondents' self-reported desire to visit the Herbert wetlands (Table 3). At the second level of the nest, respondents' choice for the doing something options depended on the level of the attributes of the alternatives (Table 4).

\section{Results and discussion}

The model estimates are presented in Table 5 . All coefficients of the variables in the utility function are highly significant and have the
Table 3. Non-attribute variable definitions

\begin{tabular}{|c|c|}
\hline Variable & Definition \\
\hline ASC1 & $\begin{array}{l}\text { Alternative-specific constant } 1 \text {-taking on } \\
\text { a value of } 1 \text { for option } B \text { and } 0 \text { for other } \\
\text { options }\end{array}$ \\
\hline ASC3 & $\begin{array}{l}\text { Alternative-specific constant } 3 \text {-taking on } \\
\text { a value of } 1 \text { for option } A \text {, status-quo } \\
\text { and } 0 \text { for other options }\end{array}$ \\
\hline Income $^{a}$ & $\begin{array}{l}\text { Respondents household income or zero if } \\
\text { absent }\end{array}$ \\
\hline Incdum $^{a}$ & $\begin{array}{l}\text { Dummy variable taking on a value of } 1 \text { for } \\
\text { respondents who did not disclose } \\
\text { household income and a zero otherwise }\end{array}$ \\
\hline $\mathrm{Age}^{a}$ & $\begin{array}{l}\text { A continuous variable indicating } \\
\text { respondent age }\end{array}$ \\
\hline Visit $^{a}$ & $\begin{array}{l}\text { A variable that takes the value of } 1 \text { for } \\
\text { those who said 'yes' to the question } \\
\text { 'Do you expect to visit Lower Herbert } \\
\text { wetlands in the future?', and zero for } \\
\text { those who said 'no' }\end{array}$ \\
\hline
\end{tabular}

${ }^{a}$ Variables were interacted with asc3 in the model.

expected sign. Attributes of the branch-choice equation, income, age, visit and the ASC3 are highly significant and carry the expected sign. The income dummy, which accounted for those $(19 \%)$ respondents who did not disclose their income, was not significant.

These results indicate that Herbert residents with higher incomes are more likely to choose an improvement option, as are those who have prior visitor experience. Some $87 \%$ of the respondents have visited the Herbert wetlands at least once, and there is a very high correlation between prior visits and future expectations to visit. Moreover, older Herbert inhabitants are more likely to choose the status-quo, which is also expected given that they are more likely to have benefited significantly from sugar industry development and that the prevailing interest and awareness of the environmental impacts of

Table 4. Attribute levels and corresponding variables

\begin{tabular}{|c|c|c|c|}
\hline Attribute & & Levels & $\begin{array}{l}\text { Variable in } \\
\text { model }\end{array}$ \\
\hline $\begin{array}{l}\text { Annual levy on land rates } \\
\text { (AUS \$) }\end{array}$ & $\begin{array}{l}\text { Option A: } \\
\text { Option B and C: }\end{array}$ & $\begin{array}{l}0 \\
10 ; 50 ; 100\end{array}$ & Rates \\
\hline $\begin{array}{l}\text { Income in region in } 2005 \\
\text { (AUS \$ million) }\end{array}$ & $\begin{array}{l}\text { Option A: } \\
\text { Option B and C: }\end{array}$ & $\begin{array}{l}400 \\
150 ; 250 ; 350\end{array}$ & Rinc \\
\hline $\begin{array}{l}\text { Teatree woodlands in } 2005 \\
\text { (ha) }\end{array}$ & $\begin{array}{l}\text { Option A: } \\
\text { Option B and C: }\end{array}$ & $\begin{array}{l}12000 \\
15000 ; 23000 ; 30000\end{array}$ & Teatree \\
\hline $\begin{array}{l}\text { Vegetation along rivers and } \\
\text { in wetlands in } 2005 \text { (ha) }\end{array}$ & $\begin{array}{l}\text { Option A: } \\
\text { Option B and C: }\end{array}$ & $\begin{array}{l}700 \\
\text { Option B, C: } 1000,2300,5000\end{array}$ & Wetland \\
\hline
\end{tabular}


Table 5. Nested logit results for the Herbert survey

\begin{tabular}{lrc}
\hline Variables & Coefficient & SE \\
\hline Utility function & & \\
ASC1 & $0.156^{a}$ & 0.073 \\
Rates & $-0.008^{b}$ & 0.001 \\
Rinc & $0.006^{b}$ & 0.001 \\
Teatree & $0.020^{b}$ & 0.008 \\
Wetland & $0.314^{b}$ & 0.032 \\
Branch choice equations & & \\
ASC3 & $-1.901^{b}$ & 0.459 \\
Income & $-9.56 \mathrm{E}-6^{b}$ & 0.000 \\
Incdum & 0.193 & 0.156 \\
Age & $0.015^{b}$ & 0.003 \\
Visit & $-0.813^{b}$ & 0.126 \\
Inclusive value parameters & & \\
Do something & $0.264^{b}$ & 0.093 \\
Do nothing & $1.000^{b}$ & 0.000 \\
Model statistics & & \\
N (choice sets) & & \\
Log likelihood & 5310 & \\
Adj. Rho-square (\%) & -1658.204 & \\
\hline
\end{tabular}

a Significance at the $5 \%$ level.

${ }^{b}$ Significance at the $1 \%$ level.

cane growing are higher amongst the lower age groups.

\section{Willingness-to-pay estimates}

The estimates of implicit prices and the 95 per cent confidence interval for the non-price attributes are presented in Table 6 . These were derived by dividing the coefficients for relevant attribute by the coefficient on rates, in Table 5. Confidence intervals for the estimates were calculated based on 1000 draws using the Krinsky and Robb (1986) procedure. The estimated values represent the marginal willingness to pay for a change in the environmental attribute concerned, ceteris paribus.

Table 6. Implicit prices estimated from the nested logit model

\begin{tabular}{lccc}
\hline Variable & $\begin{array}{c}\text { Value of a } \\
\text { single unit } \\
\text { improvement } \\
\text { (AUS \$) }\end{array}$ & \multicolumn{2}{c}{$\begin{array}{c}\text { 95\% confidence } \\
\text { interval }\end{array}$} \\
\cline { 3 - 5 } & 0.71 & 0.50 & 1.11 \\
\hline $\begin{array}{c}\text { Regional income } \\
\text { (AUS \$ million) }\end{array}$ & 2.56 & 0.45 & 5.25 \\
$\begin{array}{c}\text { Teatree woodlands } \\
(1000 \text { ha) }\end{array}$ & 39.95 & 27.52 & 61.37 \\
$\begin{array}{c}\text { Herbert wetlands } \\
\text { (100 ha) }\end{array}$ & & & \\
\hline
\end{tabular}

For instance, the regional income parameter of 0.71 indicates that the respondents are willing to forgo AUS $\$ 0.71$ to increase regional income by AUS $\$ 1$ million. It should be noted that income was used in the survey as a proxy for income and employment effects associated with the sugar industry activities in the region.

The overall WTP for environmental protection was calculated using Equation (A10) (Appendix) to solve for the compensating surplus as follows:

$$
W=-\frac{1}{\mu}\left[V_{\text {io }}-V_{\text {il }}\right]
$$

where $\mu$ is the marginal utility of income measured as the coefficient for rates; and $V_{\text {io }}$ and $V_{\text {il }}$ are respectively the utility of the current situation and the situation after improvements. A movement from status-quo (Option A in Figure 1) was compared against a new situation where the teatree area increased from 12000 to 13000 ha and the wetland area increased from 700 to 800 ha, while the regional income was held at AUS $\$ 400 \mathrm{~m}$ per year. Using means for income and socioeconomic variables, these scenarios produced a mean welfare estimate of AUS \$39.95 per household per year (Table 7).

The non-excludability of public good benefits of environmental assets implies that, once made available, the assets will potentially benefit all households. Assuming that the willingness to pay of non-respondents is the same as respondents, the value of the public asset is reflected in the sum over all households of the value placed on it. Therefore the marginal willingness-to-pay estimates for each of the two environmental attributes were aggregated over the sample district to obtain the level of welfare that could be generated to Herbert residents from improvements to teatree woodlands and wetland areas (Table 7). It must be noted that these estimates measure net marginal welfare improvements by moving from status quo to an improved position. They are, in this sense, net trade-off estimates between some of the financial and environmental values in cane area expansion.

The study examined the preservation of two land types: Lower Herbert wetlands and riparian vegetation, which currently occupy an area of 2300 ha, and teatree woodlands 
Table 7. Willingness-to-pay for environmental protection by Herbert households (AUS \$)

\begin{tabular}{lcccr}
\hline Attribute & $\begin{array}{c}\text { Area protected } \\
\text { (ha) }\end{array}$ & $\begin{array}{c}\text { Mean WTP } \\
\text { per household }\end{array}$ & $\begin{array}{c}\text { Marginal WTP } \\
\text { per household } \\
\text { per attribute }\end{array}$ & $\begin{array}{r}\text { Total } \\
\text { household } \\
\text { values for } \\
\text { Herbert }\end{array}$ \\
\hline $\begin{array}{l}\text { Teatree woodlands } \\
\text { Herbert wetlands }\end{array}$ & $\begin{array}{c}1000 \\
100\end{array}$ & & 2.56 & 18278 \\
Package & $(1000$ tea tree & 33 & 39.95 & 281260 \\
& 100 wetlands) & & & 231990 \\
\hline
\end{tabular}

Source: Australian Bureau of Statistics (1998).

${ }^{a}$ There were an estimated 7030 households in the survey region.

which currently occupy an area of 21000 ha in the Lower Herbert. The area of both land types is declining at present, primarily because of expansion in the area allocated to sugarcane production. The marginal value elicited for teatree woodlands (Table 7; column 5) of 18278 for the preservation of 1000 ha indicates a value of AUS $\$ 18$ per ha per year. In a similar way, the marginal value elicited for wetlands of AUS $\$ 281260$ per 100 ha parcel yields an annual value of 2812 per ha. These figures represent the scarcity value of the two natural land uses, and the public good value of preserving teatree woodlands and Herbert wetlands to the Herbert community. In this sense, they represent opportunity costs of clearing each type of vegetation for cane area development.

The 95 per cent confidence interval for the opportunity cost of teatree woodlands ranged from AUS $\$ 3.20$ to 36.90 per ha per year, which is less than the value of land in sugar production. However, this range of values is comparable to the value of beef production under extensive grazing. Grazing is another land-use in Herbert, which over the years, has been largely replaced by sugar cane. The corresponding confidence interval for wetlands and riparian areas was AUS $\$ 1915$ to 4315 per ha per year. This estimate compares well with the value of output obtained for sugar cane in Herbert.

\section{Integrating non-market estimates in land-use allocation}

In this study, the primary purpose of developing non-market estimates of community willingness-to-pay for environmental protection was to demonstrate their use in land-use allocation. As discussed above, we observed a remarkable congruence between willingnessto-pay values estimated in the choice model and the observed market returns for competing land uses. While this congruence enhances the validity of these value estimates for use in the decision-making process, the assessment of trade-offs between production and conservation alternatives requires careful consideration of all costs and benefits in a regional resource allocation context. Such integration involves the issues of relevance and sensitivity of WTP estimates for comparison with market derived values.

Mallawaarachchi and Quiggin (2001) provides a method to incorporate these two sources of values in regional land allocation decisions to maximise regional welfare. The method uses a programming model to determine the optimal allocation of land between conservation, cane production and cattle grazing, using disaggregated landuse data, land-quality attributes and market data to value outputs produced from sugar cane and cattle grazing. In their model simulations, the opportunity costs, or the value of natural woodlands forgone in the conversion to sugar cane, were determined on the basis of the choice modelling results discussed above.

The average value of cane land, as indicated by the shadow price of land in the Mallawaarachchi and Quiggin (2001) model, ranged from AUS $\$ 1300 /$ ha in marginal land, which is barely suitable for cane production, to AUS $\$ 2100 /$ ha in good quality land. Shadow prices of AUS $\$ 2812 /$ ha (equivalent to the estimated value of wetlands) are not unusual in better quality land, particularly those found beside river corridors, but it is unlikely that many cane properties will have shadow prices exceeding this level. The range of values estimated in the choice 
Table 8. Range of value estimates for three main land uses in Herbert (\$/ha)

\begin{tabular}{|c|c|c|c|c|}
\hline \multirow[t]{2}{*}{ Land use } & \multirow[t]{2}{*}{ Mean } & \multicolumn{2}{|c|}{ Range } & \multirow{2}{*}{$\begin{array}{l}\text { Source of } \\
\text { estimate }\end{array}$} \\
\hline & & Lower & Upper & \\
\hline $\begin{array}{l}\text { Teatree } \\
\text { woodlands }\end{array}$ & 18 & $3 \cdot 2$ & 36.9 & $\begin{array}{l}\text { Choice } \\
\text { model }\end{array}$ \\
\hline $\begin{array}{l}\text { Herbert } \\
\text { Wetlands }\end{array}$ & 2812 & 1935 & 4315 & $\begin{array}{l}\text { Choice } \\
\text { model }\end{array}$ \\
\hline Sugar cane & 1500 & -110 & 4380 & CLAM $^{a}$ \\
\hline
\end{tabular}

${ }^{a}$ Mallawaarachchi and Quiggin (2001).

model and the linked land allocation model is summarised in Table 8.

It must also be noted that, the opportunity costs of natural land estimated in this study sets a lower bound for their values for planning purposes, because further contraction of natural area would lead to an increase in the value of remaining areas due to growing scarcity. On the contrary, the real value of marketed products such as sugar tends to decline over time reflecting advances in technology, which affects both the costs of production and the availability of substitutes.

The observed compatibility between nonmarket values for wetlands and riparian vegetation estimated through the choice model, and the marginal valuations for cane land estimated through a programming model may be explained by the regular use of wetlands by Herbert residents for recreational fishing and related activities. These relatively high indirect use values are most likely influencing the high value placed on wetlands by the survey respondents. Significant current interest in the Herbert community for the restoration of degraded riparian areas could also have contributed to this assessment. Conversely, the area of remaining teatree woodlands are still large, and the level of decline in the area of teatree woodlands has been less pronounced to the residents than the rate of decline in the area of wetlands and riparian vegetation. This may have affected the relative valuation of the two vegetation types by the survey respondents. These estimates are consistent with comparative studies elsewhere (Morrison et al., 1999; Blamey et al., 2000).

It follows that optimal land-use management should, as far as possible, prevent any further diversion of wetlands to agricultural production, through planning constraints. The allocation model presented in Mallawaarachchi and Quiggin (2001), assumed that such constraints are imposed and that allocation of land to agricultural uses incorporates requirements for preservation of wetlands.

\section{Other responses}

Responses to the ancillary questions were of interest in themselves. Sixty-six per cent of the respondents indicated that they 'favour development and environment in a like manner', when asked to choose between development and environmental preservation. However, only 23\% agreed that 'economic benefits from cane growing are more important than the environmental impact of land clearing'. Some 57\% disagreed with the same statement, while $20 \%$ were noncommittal.

Sixty percent of the sample preferred a voluntary incentive scheme to encourage cane growers to preserve vegetation, to a scheme supported by a levy on land rates. Concerns about the levy were also evident during the focus group meetings. However, it was used as a payment vehicle in the survey in the absence of a superior alternative. One major concern with the levy idea was that over $70 \%$ of respondents did not believe that governments can be trusted to spend the levy on canegrowers, to support the incentive scheme. These responses were incorporated in the nested-logit model estimation to determine opportunities for improving model performance. No significant differences in performance were evident in alternative model specifications.

Nevertheless, the lack of support to the levy may have impacted on the response rate, by in particular discouraging lower income groups from returning the questionnaire. This view is also supported by the high sample estimate for household income, compared to the population estimates produced by the Australian Bureau of Statistics (1998, Table 2). It was indicated earlier that this non-response bias could have led to an overestimation of the derived estimates of implicit prices for environmental attributes in Table 6. While the household income estimates from the Australian Bureau of Statistics were used in deriving the value estimates reported in Table 7 to minimise this impact, 
caution is necessary in using the results of the study within those considerations. Particular care is necessary in interpreting these results beyond the study area, because these responses were based on specific scenarios presented to Herbert residents, reflecting the local environment. However, in terms of method development and exploration of policy strategies the study provides useful information and insights.

The general support for environmental preservation in the region was evident throughout the sample. The statement that 'canegrowers should be compensated for any production they are forced to forgo' to preserve vegetation, was supported by $50 \%$ and opposed by $32 \%$. Fifty-four per cent believed that the incentive scheme would be effective in minimising the environmental impacts of tree clearing'. The support for these statements was similar between the whole sample and the sub-sample that consisted of respondents who derived their major share of household income from the sugar industry.

\section{Conclusions}

Estimates of the non-use values of environmental assets in cane growing areas in Australia were derived in this study using the Herbert River District as an example. To our knowledge, this is the first occasion that such estimates have been produced in relation to sugar industry land use. These value estimates indicate that the Herbert residents, who benefit significantly from the sugar industry, are willing to pay for environmental protection.

The results also indicate that, between the two environmental choices presented to the community during the study, the preference for wetland preservation is much higher than that for teatree woodlands. This observation is consistent with reality where the available area of wetlands has declined faster than the area of teatree woodlands, and this relative scarcity value is reflected in the estimates. Furthermore, the regular recreational use of Herbert wetlands by the residents and their growing conservation motives for riparian areas may also have contributed to this assessment.

In general, study suggests that communities that benefit directly from agricultural developments concurrently perceive the benefits of preserving environmental attributes that are replaced by development activities, and that such perceptions follow the notion of scarcity making them amenable to economic estimation.

The results indicate that the environmental values of wetlands are comparable to returns from commercial production of sugarcane and that the values of teatree woodlands are comparable to returns from extensive grazing. It is argued that land allocation policies should recognise these values in tandem with commercial benefits of production to ensure that resources are used more efficiently. More specifically, sugar industry stakeholders in Herbert can make use of these estimates in guiding their planning and management decisions to conserve environmental assets and to minimise the impact of future developments on the environment. Results, however, are applicable in a more global sense where it is demonstrated that incorporation of full economic costs, of both production and environmental benefits, in land-allocation decisions improves the net social benefits of resource use options. Using choice modelling estimates in regional programming models to evaluate alternative land-allocation strategies provide a useful tool for estimating the trade-offs between direct financial and environmental impacts in development activities. Non-market estimates of environmental values integrated into production models in this manner make them readily applicable to land-use planning, and become valuable as a management tool to mitigate harmful environmental consequences of production activities.

\section{Acknowledgements}

John Quiggin and Owen Stanley offered valuable insights to the interpretation of survey results. The assistance of Sam Ebert and Sonja Slatter in survey administration is gratefully acknowledged.

\section{References}

Adamowicz, W., Boxall, P., Williams, M. and Louviere, J. (1998). Stated preference approaches for measuring passive use values: choice experiments and contingent valuation. American Journal of Agricultural Economics 80, 64-75. 
Australian Bureau of Statistics (1998). Integrated Regional Data Base (IRDB). Canberra: Australian Bureau of Statistics (ABS).

Ben-Akiva, M. and Lerman, S. R. (1985). Discrete Choice Analysis: Theory and Application to Travel Demand. Cambridge: MIT Press.

Bennett, J. (1996). The contingent valuation method: a post-kakadu assessment. Agenda 5, 185-194.

Blamey, R. K., Rolfe, J. C., Bennett, J. W. and Morrison, M. D. (1997). Environmental Choice Modelling: Issues and Qualitative Insights. Canberra: Department of Economics and Management, ADFA.

Blamey, R. K., Gordon, J. and Chapman, R. (1999). Choice modelling: assessing the environmental values of water supply options. Australian Journal of Agricultural and Resource Economics 43, 337-358.

Blamey, R., Rolfe, J., Bennett, J. and Morrison, M. (2000). Valuing remnant vegetation in Central Queensland using choice modelling. The Australian Journal of Agricultural and Resource Economics 44, 439-456.

Bramley, R. G. V., Cook, S. E., Cox, D. R. V., McMahon, G. G. and Roth, C. H. (1998). Precision agriculture: what is it and what can it offer the Australian sugar industry? Proceedings of the Australian Society of Sugar Cane Technologists (D. M. Hogarth, ed.), 20, 188-195.

Cameron, T. A. and Quiggin, J. (1994). Estimation using contingent valuation data from a dichotomous choice with follow-up questionnaire. Journal of Environmental Economics and Management 27, 218-234.

Canegrowers (1997). Sugar industry puts tariff in perspective. Australian Canegrower 19, 5 .

Canegrowers (1998). Code of Practice for Sustainable Cane Growing. Brisbane: Canegrowers.

Carson, R. T., Louviere, J. J., Anderson, D. A. Arabie, P., Bunch, D. S., Hensher, D. A. et al. (1994). Experimental analysis of choice. Marketing Letters 5, 351-368.

Cochran, W. G. (1977). Sampling Techniques. New York: Wiley.

Costanza, R., d'Arge, R., de Groot, R., Farber, S., Grasso, M., Hannon, B. et al. (1997). The value of the world's ecosystem services and natural capital. Nature 387, 253-260.

Diener, A. A., Muller, R. A. and Robb, A. L. (1998). Willingness-to-Pay for Improved Air Quality in Hamilton-Wentworth: A Choice Experiment. Hamilton, Ontario: Department of Economics, McMaster University.

Greene, W. H. (1998). LIMDEP, Version 7.0. Castle Hill, NSW, Australia: Econometric Software.

Gutteridge, Haskins and Davey (1996). Environmental Audit of the Queensland Canegrowing Industry. Brisbane: Canegrowers.

Hanemann, W. M. (1984). Applied Welfare Analysis with Quantitative Response Models. Berkeley, CA: University of California.

Hanink, D. M. and Cromley, R. G. (1998). Landuse allocation in the absence of complete market values. Journal of Regional Science 38, 465-480.
Hensher, D. A. and Johnson, L. W. (1981). Applied Discrete Choice Modelling. New York: John Wiley and Sons.

Herriges, J. A. and Kling, C. L. (1997). The performance of nested logit models when welfare estimation is the goal. American Journal of Agricultural Economics 79, 792-802.

Johnson, A. K. L., McDonald, G. T., Shrubsole, D. and Walker, D. H. (1997). Sharing the land: the sugar industry as a part of the wider landscape. In Intensive Sugar Cane Production: Meeting the Challenges beyond 2000 (B. A. Keating and J. R. Wilson, eds), pp. 361-380. Wallingford: CAB International.

Johnson, A. K. L., Ebert, S. P. and Murray, A. E. (1998). Spatial and temporal distribution of freshwater wetlands and riparian forests in river catchments adjacent to the Great Barrier Reef Marine Park. In Protection of wetlands adjacent to the Great Barrier Reef, Great Barrier Reef Marine Park Authority, Workshop Series.

Kling, C. L. and Thomson, C. J. (1996). The implications of model specification for welfare estimates in nested logit models. American Journal of Agricultural Economics 78, 103-114.

Krinsky, I. and Robb, A. L. (1986). On approximating the statistical properties of elasticities. Review of Economics and Statistics 72, 189-190.

Louviere, J. J. and Hensher, D. A. (1982). On the design and analysis of simulated choice or allocation experiments in travel choice modelling. Transportation Research 890, 11-17.

Mallawaarachchi, T. (1998). Resource use conflicts in a multi-user environment: land assignment in the Australian sugar industry. Australian Agribusiness Review 6, (http://www.agribusiness.asn.au/agribusinessreview/SugarIndustry. html).

Mallawaarachchi, T. and Quiggin, J. (2001). Modelling socially optimal land allocations for sugar cane growing in North Queensland: a linked mathematical programming and choice modelling study. Australian Journal of Agricultural and Resource Economics 45, (in press).

Mary Maher and Associates (1996). Environmental Issues and the Assignment System. Sydney: Boston Consulting Group.

McFadden, D. (1974). Conditional logit analysis of qualitative choice behavior. In Frontiers in Econometrics (P. Zarembka, ed.), pp. 105-142. New York: Academic Press.

McFadden, D. (1978). Spatial interaction theory and planning models (A. Karlquist, L. Lundquist, F. Snikars and J. W. Weibull, eds), pp. 75-96. Amsterdam: North-Holland.

Menkhaus, S. and Lober, D. J. (1996). International ecotourism and the valuation of tropical rainforests in Costa Rica. Journal of Environmental Management 47, 1-10.

Mitchell, R. C. and Carson, R. (1989). Using Surveys to Value Public Goods: The Contingent Valuation Method. Washington, DC: Resources for the future.

Morrison, M., Blamey, R. K., Bennett, J. W. and Louviere, J. (1996). A comparison of stated preference techniques for estimating environmental 
values. Research Report. Canberra: Department of Economics and Management, ADFA.

Morrison, M., Bennett, J. W. and Blamey, R. K. (1997). Designing choice modelling surveys using focus groups: Results from the Macquarie Marshes and Gwydir Wetlands Case studies. Research Report. Canberra: Department of Economics and Management, ADFA.

Morrison, M. D., Bennett, J. W. and Blamey, R. K. (1999). Valuing improved wetland quality using choice modelling. Water Resources Research 35, 2805-2814.

Morrison, M. D., Blamey, R. K. and Bennett, J. W. (2000). Minimising payment vehicle bias in contingent valuation studies. Environmental and Resource Economics 16, 407-422.

Pearce, D. (1993). Economic Values and the Natural World. London: Earthscan Publications Ltd.

Rayment, G. E. and Neil, D. (1997). Sources of material in river discharge. In The Great Barrier Reef Science, Use and Management: A National Conference pp. 42-58. Townsville: Great Barrier Reef Marine Park Authority.

Samuelson, W. and Zeckhauser, R. (1988). Status quo bias in decision making. Journal of Risk and Uncertainty 1, 7-59.

Smith, V. K. (1996). Estimating Economic Values for Nature: Methods for Nonmarket Valuation. Cheltenham, UK: Edward Elgar.

Streever, W. J., Callaghan-Perry, M., Searles, A., Stevens, T. and Svoboda, P. (1998). Public attitudes and values for wetland conservation in New South wales, Australia. Journal of Environmental Management 54, 1-14.

Train, K. E., McFadden, D. L. and Ben-Akiva, M. (1987). The demand for local telephone service: a fully discrete model of residential calling patterns and service choices. Rand Journal of Economics 18, 109-123.

Vella, K. (1997). Local Government Solutions to Mangrove and Wetland Conservation. BSc Honours Thesis. St Lucia: University of Queensland.

White, P. CL. and Lovett, J. C. (1999). Public preferences and willingness-to-pay for nature conservation in the North York Moors National Park, UK. Journal of Environmental Management 55, 1-13.

\section{Appendix}

\section{Theoretical basis of choice modelling}

The CM approach is based on random utility theory (RUT) (McFadden, 1974). According to RUT, the respondent $i$ derives utility $U_{\mathrm{ij}}$ from the alternative $j$ in choice set C. $U_{\mathrm{ij}}$ is assumed to be a function of both the attributes of the alternatives in choice set $\mathrm{C}\left(X_{\mathrm{jk}}\right.$ representing the $k$ th attribute value of the $j$ th alternative) and characteristics of the individual $S_{\mathrm{i}}$. $U_{\mathrm{ij}}$ is assumed to comprise an observed component $V_{\mathrm{ij}}$ and an unobserved component $e_{\mathrm{ij}}$. We therefore have:

$$
U_{\mathrm{ij}}=V_{\mathrm{ij}}\left(X_{\mathrm{ij}}, S_{\mathrm{i}}\right)+e_{\mathrm{ij}}
$$

Respondent $i$ will choose alternative $h$ in preference to $j$, if $U_{\mathrm{ih}}>U_{\mathrm{ij}}$. Hence:

$$
\begin{aligned}
P_{\mathrm{ih}}= & P\left(U_{\mathrm{ih}}>U_{\mathrm{ij}}\right), \text { for all } j \text { in } \mathrm{C}, j \neq h \\
= & P\left(V_{\mathrm{ih}}>V_{\mathrm{ij}}>e_{\mathrm{ij}}-e_{\mathrm{ih}}\right), \\
& \quad \text { for all } j \text { in } \mathrm{C}, j \neq h
\end{aligned}
$$

The error term, $e_{\mathrm{ij}}$, is typically assumed to be independently and identically distributed with a Gumbell distribution. This gives rise to the multinomial logit model (MNL) applicable to discrete choice modelling:

$$
P_{\mathrm{ih}}=\frac{\exp \left[\lambda V_{\mathrm{ih}}\right]}{\sum_{\mathrm{j} \in \mathrm{C}} \exp \left[\lambda V_{\mathrm{ij}}\right]}
$$

where $\lambda$ is a scale parameter, which is inversely proportional to the variance of the error term and normalised to 1 for any given data set (Ben-Akiva and Lerman, 1985). A linear-in-parameters utility function such as the following for alternative $j$ is often used for this model:

$$
\begin{aligned}
V_{\mathrm{ij}}= & A S C_{\mathrm{j}}+\beta_{1} X_{1}+\beta_{2} X_{2}+\beta_{3} X_{3} \\
& +\ldots \beta_{\mathrm{k}} X_{\mathrm{k}}+\ldots \beta_{\mathrm{n}} X_{\mathrm{n}}+\gamma_{1}\left(S_{1} \cdot A S C_{\mathrm{j}}\right) \\
& +\ldots+\gamma_{\mathrm{m}}\left(S_{\mathrm{m}} \cdot A S C_{\mathrm{j}}\right)
\end{aligned}
$$

where there are $n$ attributes with generic coefficients across alternatives, and $m$ individual-specific variables multiplied by an alternative-specific-constant (ASC). The ASCs capture the mean effect of the unobserved factors in the error terms for each alternative. This provides a zero mean for unobserved utility and causes the average probability of selecting each alternative over the sample to equal the proportion of respondents actually choosing that alternative. Socioeconomic and attitudinal variables are included by interacting them with the alternative-specific constants, or with attributes from the choice sets. 
The inclusion of ASC's helps mitigate inaccuracies due to violations in the assumption of independence of irrelevant alternatives (IIA) (Train, 1986). ${ }^{4}$ This assumption requires that the ratio of the choice probabilities for any two alternatives be unaffected by the addition or removal of alternatives. This is equivalent to assuming that the random error components of utility are uncorrelated between choices and have the same variance (Carson et al., 1994). Violations of the IIA assumption render the MNL model inappropriate.

\section{Nested logit model}

An alternative way to avoid IIA violations is to allow for correlations among the error terms within different groups or classes of alternatives by estimating a nested logit model (McFadden, 1978). In a two levelnested logit model, the probability of an individual choosing the $h$ th alternative in class $r\left(P_{\mathrm{hr}}\right)$ is represented as:

$$
P_{\mathrm{hr}}=P(h / r) \cdot P(r)
$$

where $P(h / r)$ is the probability of the individual choosing the $h$ th alternative, conditional on choosing the $r$ th class of outcome, and $P(r)$ is the probability that the individual chooses the $r$ th class. Following Kling and Thomson (1996):

$$
\begin{array}{r}
P_{\mathrm{i}}(h / r)=\frac{\exp \left[V_{\mathrm{ihr}} / \alpha\right]}{\exp \left[I_{\mathrm{r}}\right]} \\
P_{\mathrm{i}}(r)=\frac{\exp \left[\alpha_{\mathrm{r}} I_{\mathrm{r}}\right]}{\sum_{\mathrm{k}=1}^{\mathrm{R}} \exp \left[\alpha_{\mathrm{k}} I_{\mathrm{k}}\right]}
\end{array}
$$

where:

$$
I_{\mathrm{r}}=\log \left[\sum_{\mathrm{i}=1}^{\mathrm{jr}} \exp \left(V_{\mathrm{ir}} / \alpha_{\mathrm{r}}\right)\right]
$$

$I_{\mathrm{r}}$ is referred to as the inclusive value. This is a measure of the expected maximum utility from the alternatives associated with the $r$ th class of alternatives. The coefficient of the inclusive value $\left(\alpha_{\mathrm{r}}\right)$ measures substitutability across alternatives. When substitutability is

$\overline{{ }^{4} \text { This assumption arises because of the independence of }}$ irrelevant options (IIO) assumption. greater within rather than between alternatives, $0<\alpha_{\mathrm{r}}<1$, respondents will shift to other alternatives in the branch more readily than they will shift to other branches (Train et al., 1987). The popularity of the nested logit model is in part due to its conformity with how respondents naturally behave in making decisions.

Welfare estimates are usually obtained in CM studies using the following general formula described by Hanemann (1984):

$$
W=-\frac{1}{\mu}\left[\ln \sum_{\mathrm{i} \in \mathrm{C}} e^{V_{\mathrm{i} 0}}-\ln \sum_{\mathrm{i} \in \mathrm{C}} e^{V_{\mathrm{i} 1}}\right]
$$

where $\mu$ is the marginal utility of income, $V_{\mathrm{i} 0}$ and $V_{\mathrm{i} 1}$ represent the indirect observable utility before and after the change under consideration, and $\mathrm{C}$ is the choice set. In most CM applications, the coefficient of the monetary attribute is taken as an estimate of $\mu$. Changes in $V_{\mathrm{i} 0}$ or $V_{\mathrm{i} 1}$ can arise from changes in the attributes of alternatives or the removal (or addition) of alternatives altogether. For example, in recreational site studies where alternatives are substitutes in consumption, the removal of an alternative from the choice set might correspond to a site closure, which one would expect to result in a welfare loss. When alternatives are substitutes in 'production', for example, when a single parcel of land has to be chosen from a set of suitable land parcels, the removal of alternatives can be used to estimate selection probabilities and welfare implications based on different sets of parcels.

When the choice set includes a single before and after policy option, Equation (A9) reduces to:

$$
\begin{aligned}
W & =-\frac{1}{\mu}\left[\ln \left(e^{V_{\mathrm{i} 0}}\right)-\ln \left(e^{V_{\mathrm{i} 1}}\right)\right] \\
& =-\frac{1}{\mu}\left[V_{\mathrm{i} 0}-V_{\mathrm{i} 1}\right]
\end{aligned}
$$

In the case of changes in a single attribute using a linear-in-parameters utility function, this further reduces to $-\beta_{\mathrm{j}} / \mu$. This is equivalent to calculating the ratio of marginal utilities for a given attribute, $h$, and the monetary attribute, $m$, or the marginal rate of substitution $\left(M R S_{\mathrm{h}, \mathrm{m}}\right)$ (Hensher and Johnson, 1981). Kling and Thomson (1996) and Herriges and Kling (1997) discuss welfare estimation in the nested logit case. 